\title{
Fabrication and characterization of PDLLA/pyrite composite bone scaffold for osteoblast culture
}

\author{
LIFANG ZHANG ${ }^{1, *}$, YANYAN ZHENG ${ }^{\mathbf{1 , 2}}$ and CHENGDONG XIONG ${ }^{\mathbf{1}}$ \\ ${ }^{1}$ Chengdu Institute of Organic Chemistry, Chinese Academy of Sciences, Chengdu 610041, People's Republic of China \\ ${ }^{2}$ University of Chinese Academy of Sciences, Beijing 100049, People's Republic of China
}

MS received 30 July 2014

\begin{abstract}
A series of highly interconnected porous poly(D,L-lactide acid) (PDLLA)/pyrite (Zi-Ran-Tong, FeS 2 ) scaffold containing 5-20\% of pyrite was fabricated by particle leaching combined with the thermal-induced phase separation method. Pyrite ( $\mathrm{FeS}_{2}$, named as $\mathrm{Zi}$-Ran-Tong in Chinese medicine), as a traditional Chinese medicine, has been used in the Chinese population to treat bone diseases and to promote bone healing. The mechanical properties of the PDLLA scaffold were significantly enhanced after the addition of pyrite. The osteoblastic ROS17/2.8 cell line was used and seeded on the PDLLA/pyrite scaffold to study its potential to support the growth of osteoblastic cells and to estimate the optimal dose of pyrite for bone tissue engineering. The effects of pyrite on cell proliferation and differentiation were evaluated by 3-[4, 5-dimethylthiazol-2-yl]-2, 5-diphenyltetrazolium bromide and alkaline phosphatase activity assay. The cells on the porous composite scaffold formed a continuous layer on the outer and inner surface observed by scanning electron microscopy and fluorescence microscope. The results strongly suggested that the PDLLA/pyrite composite scaffold could stimulate the growth of ROS17/2.8 cells in vitro and it could be potentially used as a scaffold for bone tissue engineering.
\end{abstract}

Keywords. Polylactic acid; Chinese herbal medicine; pyrite; scaffold; bone regeneration; cell culture.

\section{Introduction}

Bone scaffolds are designed to regenerate natural bone tissues or to create biological substitutes for defective bone tissues through the use of cells. The success of these approaches is largely dependent on the scaffold properties such as degradability, biocompatibility, highly interconnected porosity and mechanical integrity. ${ }^{1,2}$ Poly(D,L-lactide acid) (PDLLA) polymer has been widely used to fabricate bone scaffolds due to its biocompatibility and biodegradability. The poor osteoconductivity of the pure polymer scaffold has led to the incorporation of bioceramics such as hydroxyapatite (HA), $\beta$-tricalcium phosphate $(\beta$-TCP) and biphasic calcium phosphate to the polymer scaffold to improve its osteoconductivity. Additionally, the relatively low mechanical properties of the pure polymer scaffold could also be improved by bioceramic. ${ }^{3-5}$

Pyrite ( $\mathrm{FeS}_{2}$, named as $\mathrm{Zi}$-Ran-Tong in Chinese medicine), as a traditional Chinese medicine, has been used in the Chinese population to treat bone diseases and to promote bone healing for thousands of years. Pyrite frequently appears in traditional prescriptions for bone and tendon injuries. For example, 47 of the 107 fracture prescriptions collected in the Encyclopedia of Esoteric Prescriptions in Traditional Chinese Medicine contain pyrite as one of the main

\footnotetext{
*Author for correspondence (zhanglfcioc@ 163.com)
}

ingredients. ${ }^{6-8}$ Huang and You $^{9}$ examined the effect of a herbal medicine, Jie-Guu-Saan, which contains pyrite on experimental fracture healing in rats. The results showed that the groups treated with herbal medicine were healed more rapidly and thoroughly than the control group with respect to collagen formation and bone cell metabolism. The present research focuses on the direct cellular level effect of pyrite on bone cells. Feng and $\mathrm{Fu}^{10}$ reported that the single pyrite enhances the number of mineral nodes of osteoblasts and promotes the expression of the insulin-like growth factors in vitro.

In this study, for the first time, the pyrite was incorporated into the porous PDLLA scaffold as a bioactive material. The aim of this work is to study its potential to support the growth of osteoblastic cells and to estimate its optimal dose for bone tissue engineering. The highly interconnected porous PDLLA/pyrite scaffold containing 5-20\% of pyrite was fabricated using a particle-leaching combined with the thermal-induced phase separation (TIPS) method. The porous PDLLA/pyrite scaffold was characterized in terms of morphology, porosity and surface wettability. The effects of pyrite on ROS17/2.8 cell proliferation and differentiation were evaluated by 3-[4,5-dimethylthiazol-2-yl]2, 5-diphenyltetrazolium bromide (MTT) and alkaline phosphatase (ALP) activity assay. The morphologies of the cell cultured on the porous composite scaffolds were observed by scanning electron microscopy (SEM) and fluorescence microscope. 


\section{Materials and methods}

\subsection{Materials}

Poly-D-L-lactide $\left(M_{\eta}=130 \mathrm{kDa}\right)$ were obtained from Sichuan Dikang Sci\&Tech Pharmaceutical Co., Ltd (Chengdu, China). Pyrite $\left(\mathrm{FeS}_{2}\right)$ was purchased from The West China College of Medicine, Sichuan University. Dulbecco's modified Eagle's medium (DMEM) and other culture media and supplements were obtained from Invitrogen (Paisley, UK). All other reagents were analytical grade and used without further purification.

\subsection{Fabrication of PDLLA/pyrite scaffolds}

A series of porous PDLLA/pyrite scaffolds (PP5, PP10 and PP20, contain 5, 10 and $20 \%$ ( $\left.w_{\text {pyrite }} / w_{\text {PDLLA }}\right)$ of pyrite, respectively) was fabricated by a particle leaching combined with the TIPS method. Briefly, various amounts $(0.25,0.5$ and $1 \mathrm{~g}$ ) of pyrite powder was dispersed in 1,4-dioxane (15 ml) and distilled water (1,4-dioxane/distilled water $=87 / 13$, $\mathrm{v} / \mathrm{v}$ ) composite solvent under stirring. PDLLA (5 g) was then added into these suspensions. By maintaining the mixtures for $30 \mathrm{~min}$ at $40^{\circ} \mathrm{C}$, an elastic gel was produced. The elastic polymer/pyrite gel was mixed homogeneously with the sieved $\mathrm{NH}_{4} \mathrm{HCO}_{3}$ salt particles (salt particle size: 150$250 \mu \mathrm{m}$; weight ratio of salt/PDLLA and pyrite: 5/1). The mixture of polymer/pyrite/salt was cast into a disk-shaped glass mould ( $9 \mathrm{~mm}$ in diameter and $5 \mathrm{~mm}$ in thickness), cooled rapidly in a $-30^{\circ} \mathrm{C}$ refrigerator and then freeze-dried by a freeze-dryer (FD-1, BIOKING). After $48 \mathrm{~h}$, the solid samples were removed from the freeze-dryer and immersed in distilled water for $24 \mathrm{~h}$ to remove the salt by leaching. The distilled water was refreshed at 4 hourly intervals. The samples were then placed in a vacuum-dryer for $48 \mathrm{~h}$ at $35^{\circ} \mathrm{C}$ to remove any remaining solvent and $\mathrm{NH}_{4} \mathrm{HCO}_{3}$ salt $\left(\mathrm{NH}_{4} \mathrm{HCO}_{3} \rightarrow \mathrm{NH}_{3} \uparrow+\mathrm{CO}_{2} \uparrow+\mathrm{H}_{2} \mathrm{O}\right)$. In this way, PDLLA/pyrite scaffold with a well-developed porous structure was prepared.

The PDLLA scaffold without pyrite particles was also prepared by this method.

\subsection{Characterization of the scaffold}

2.3a Morphology: The porous PDLLA scaffolds and the PDLLA/pyrite scaffolds were coated with gold and their morphologies were examined by SEM (JSM-5900, Japan).

2.3b Mechanical properties: The porous PDLLA/pyrite scaffolds (PP5, PP10 and PP20) and the PDLLA scaffold were subjected to a compression test using an electromechanical universal testing machine (SANS CMT4503, China Shenzhen) at a crosshead speed of $2 \mathrm{~mm} \mathrm{~min}^{-1}$. The compressive offset yield stress was determined from the stress-strain curve at a $2 \%$ strain. The compressive modulus was determined from the slope at the initial stage.
Five replicate determinations were undertaken for each formulation.

2.3c Open porosity: The open porosity can be calculated by the liquid displacement method. ${ }^{11}$ The scaffold is submerged in a known volume $(V 1)$ of ethanol that is not a solvent for the scaffold and a series of brief evacuation repressurization cycles are conducted to force the liquid into the pores of the scaffold. After these cycles the volume of the liquid and liquid-impregnated scaffold is $V 2$. When the liquid-impregnated scaffold is removed, the remaining liquid volume is $V 3$ and open porosity is given as

$$
\eta=(V 1-V 3) /(V 2-V 3) \text {. }
$$

The above test was performed in triplicate for each kind of scaffold fabricated in this study.

\subsection{Osteoblastic culture}

The immortalized rat osteoblastic ROS17/2.8 cell line (obtained from The West China College of Medicine, Sichuan University) was used in this study. These cells were incubated in a humidified atmosphere of $5 \% \mathrm{CO}_{2}$ at $37^{\circ} \mathrm{C}$. Cells were cultured in Dulbecco's modified Eagle's medium (DMEM, Invitrogen, Paisley, UK) and supplemented with $10 \%$ fetal bovine serum (FBS, Invitrogen, Paisley, UK), $100 \mathrm{mg} \mathrm{ml}^{-1}$ streptomycin and $100 \mathrm{U} \mathrm{ml}^{-1}$ penicillin. The culture media was changed every alternate day.

2.4a Analysis of cytotoxicity and proliferation of the ROS17/2.8 cells: The PDLLA scaffolds and the PDLLA/pyrite scaffolds (PP5, PP10 and PP20) were cut into round slices ( $9 \mathrm{~mm}$ in diameter and $1 \mathrm{~mm}$ in thickness) and were sterilized by gamma radiation $(25 \mathrm{kGy}$ dose, Co-60 gamma irradiator). The sterilized scaffold slices were placed into a 24-well plate and the cells were seeded into the well plates at a density of $2 \times 10^{4}$ cells per well. All the cells were cultured at $37^{\circ} \mathrm{C}$ in a humidified atmosphere with $5 \%$ $\mathrm{CO}_{2}$. The medium was changed every 3 days. For each time point, six replicate determinations were undertaken (three for the fluorescent staining observation and three for the MTT assay).

Fluorescent staining and observation: After each time point, the samples were stained with $0.01 \%$ AO (acridine orange) for $5 \mathrm{~min}$, washed with PBS and examined under a fluorescence microscope (OLYMPUS B ×60). For each time point, the test was performed in triplicate.

MTT assay: A MTT assay was used to assess cell proliferation by measuring mitochondrial succinate dehydrogenase activity. ${ }^{12}$ After $1,3,6,12$ and 21 days, MTT solution (200 $\mu \mathrm{l})\left(5 \mathrm{mg} \mathrm{ml}^{-1}\right.$, Sigma) was added to each well. The cells were cultured at $37^{\circ} \mathrm{C}$ in a humidified atmosphere with $5 \% \mathrm{CO}_{2}$ for $4 \mathrm{~h}$ to allow the formation of formazan crystals. After culture medium was aspirated off, DMSO (dimethylsulphoxide) $(1 \mathrm{ml})$ was added into each well. The well plate 
was left on a shaking platform for $10 \mathrm{~min}$. Thereafter, the solution $(200 \mu \mathrm{l})$ was collected and pipetted into a 96-well plate. The plates were read on a Microplate reader (BIORAD, model 550), using a test wavelength of $570 \mathrm{~nm}$. The cells without a scaffold served as the negative control in this study.

2.4b Assay for ALP activity: ALP activity was determined with 4-nitro-phenyl phosphate (Roche Reagent, German) as the substrate. Sample volumes of $0.02 \mathrm{ml}$ were added to $0.2 \mathrm{ml}$ regent solution ( $\mathrm{pH}$ 10.4). Enzyme activity was quantified by absorbance measurements at $410 \mathrm{~nm}$ for the amount of 4-nitrophenoxide ion. The enzyme activity of ALP was expressed as $1 \mathrm{U}^{-1}$ which is defined as $1 \mu \mathrm{mol}$ of 4-nitrophenoxide ion produced per minute per litre.

2.4c SEM: For SEM observation, the ROS17/2.8 $\left(2 \times 10^{4}\right.$ cells per well) cells were cultured on the porous scaffolds, and fixed in $0.5 \%$ glutaraldehyde in $0.1 \mathrm{M}$ phosphate buffer solution (PBS) at $4^{\circ} \mathrm{C}$ for $1 \mathrm{~h}$. The ROS17/2.8 cells on the scaffolds were washed twice with PBS for $10 \mathrm{~min}$, and then dehydrated by increasing the concentration of alcohol (50, $70,80,90,95,99$ and $2 \times 100 \%$ ). To avoid the distortion of the polymer scaffold, the critical point drying of specimens undertaken with liquid $\mathrm{CO}_{2}$ was not performed. The specimens were sputter-coated with gold and examined by SEM. The growth of cells on the scaffolds was observed at 6,12 and 14 days.

\subsection{Statistical analysis}

All the above tests were performed in triplicate. The data were analysed statistically using a t-test with SPSS 11.5 for windows. Statistical tests were performed at a $95 \%$ significance level $(p<0.05)$.

\section{Results and discussion}

\subsection{Morphology and mechanical properties}

As a bone scaffold in tissue engineering, a highly interconnected porous structure and high mechanical properties were required. Figure 1 shows the morphologies of the PDLLA scaffold (figure 1a and b) and the PDLLA/pyrite scaffold PP5 (figure 1c and d), PP10 (figure 1e and f) and PP20 (figure 1g and $h$ ) fabricated by the particle leaching combined with the TIPS method. The expected 3D interconnected porous structure was evident. From the SEM pictures, it was observed that the pore size of the pores were about $150-250 \mu \mathrm{m}$. In addition, small pores of $20-50 \mu \mathrm{m}$ formed in the phase separation process in pore walls could be observed. Table 1 shows the porosity of the PDLLA scaffold and the PDLLA/
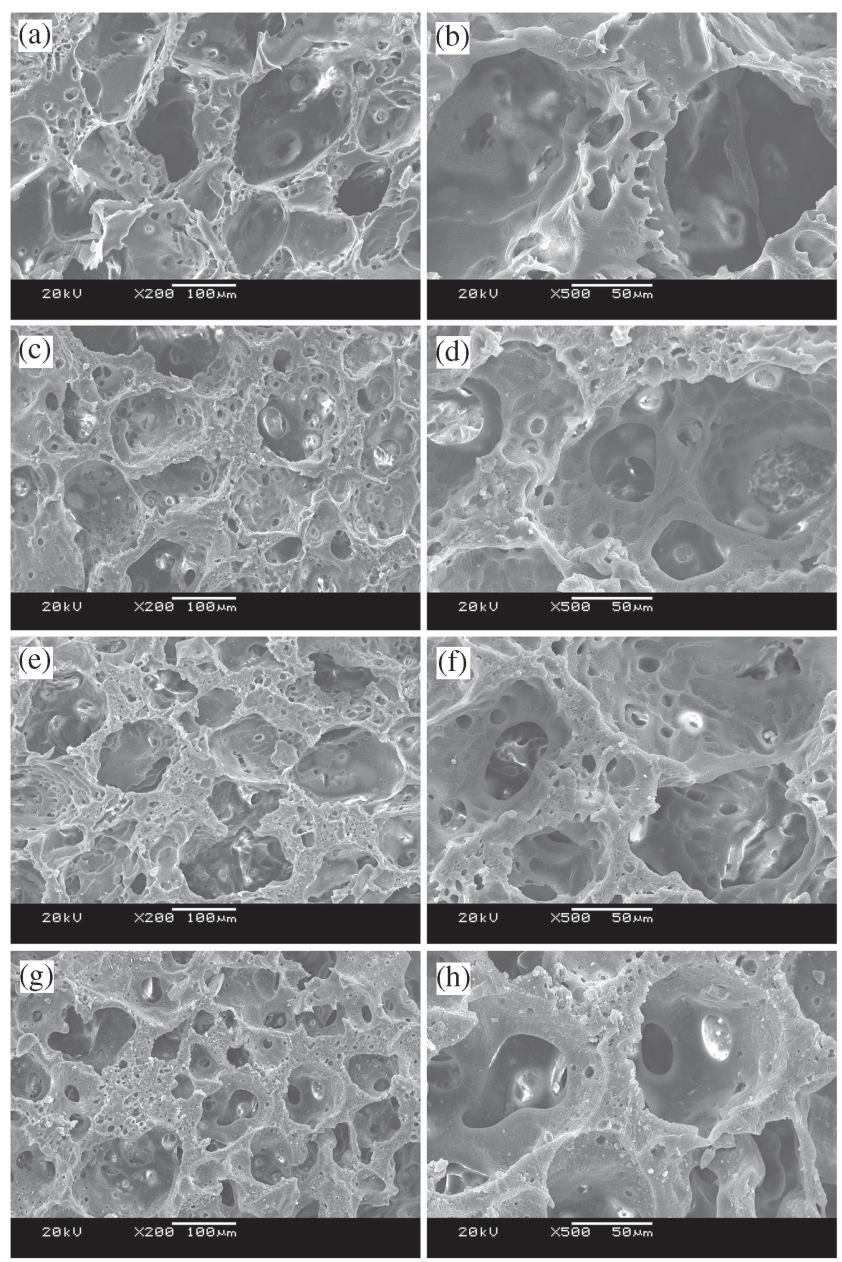

Figure 1. Morphology of the porous PDLLA scaffold $(\mathbf{a}, \mathbf{b})$ and PDLLA/pyrite scaffold (PP5: c, d; PP10: e, f; PP20: g, h).

Table 1. Open porosity of the PDLLA scaffold and the PDLLA/pyrite scaffolds PP5, PP10 and PP20.

\begin{tabular}{lc}
\hline Samples & Porosity $(\% \pm \mathrm{SD}, n=3)$ \\
\hline PDLLA & $84.5 \pm 0.9$ \\
PP5 & $83.3 \pm 2.1$ \\
PP10 & $84.1 \pm 1.2$ \\
PP20 & $82.7 \pm 2.3$ \\
\hline
\end{tabular}

pyrite scaffolds. Clearly, there was no obvious difference between the PDLLA scaffold and the PDLLA/pyrite scaffolds.

Compared to the bioceramic scaffold, the polymer scaffold not possesses relatively high mechanical properties, but with controllable degradation rates. Therefore, bioceramics (HA, $\beta$-TCP, etc.) were generally incorporated into the polymer scaffolds to improve their mechanical properties. ${ }^{3-5}$ The mechanical properties of the scaffold in this study were also significantly enhanced by the pyrite particles. From table 2, there was an increase in the mechanical 
Table 2. Mechanical properties of the PDLLA scaffold and the PDLLA/pyrite scaffolds PP5, PP10 and PP20.

\begin{tabular}{lcc}
\hline & $\begin{array}{c}\text { Compressive offset yield } \\
\text { strength at } 2 \% \text { of strain } \\
(\mathrm{MPa} \pm \mathrm{SD}, n=5)\end{array}$ & $\begin{array}{c}\text { Compressive modulus } \\
(\mathrm{MPa} \pm \mathrm{SD}, n=5)\end{array}$ \\
Samples & $0.62 \pm 0.03$ & $6.53 \pm 0.04$ \\
PDLLA & $0.71 \pm 0.02$ & $7.89 \pm 0.05$ \\
PP5 & $0.92 \pm 0.04$ & $11.65 \pm 0.04$ \\
PP10 & $0.94 \pm 0.05$ & $17.68 \pm 0.07$ \\
PP20 & & \\
\hline
\end{tabular}
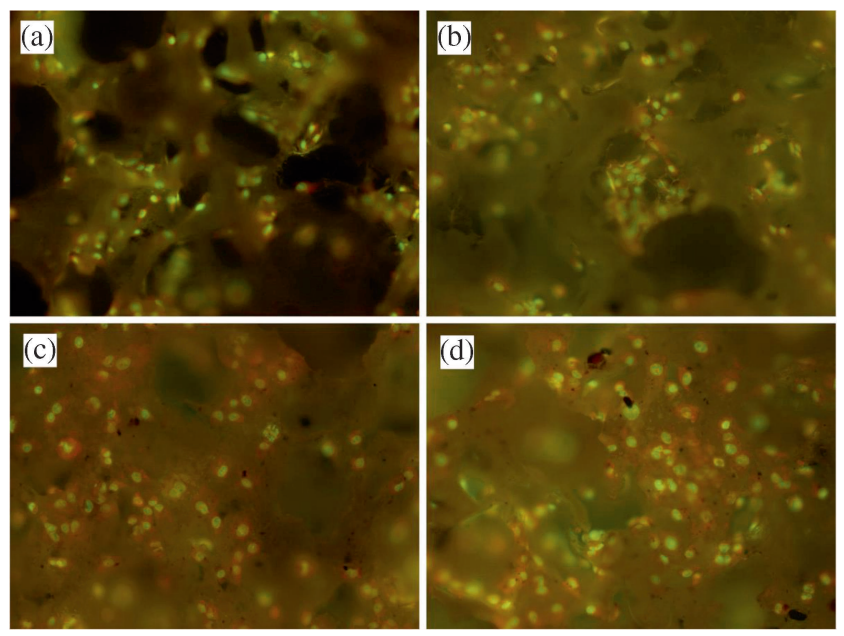

Figure 2. Fluorescent micrographs of the osteoblasts cultured on PDLLA scaffold (a) and PDLLA/pyrite scaffolds (b: PP5; c: PP10; d: PP20) after 1 day.

properties with a decrease in the ratio of PDLLA/pyrite. Also, the compressive modulus was also increased from 6.53 to $17.68 \mathrm{MPa}$ with a decrease in the ratio of PDLLA/ pyrite.

\subsection{Cell growth on the bone scaffolds}

Osteoblasts were cultured on the PDDLA scaffold and PDLLA/pyrite scaffolds (PP5, PP10 and PP20) in order to determine the biocompatibility of these scaffolds and the effects of pyrite on the growth of osteoblasts. The fluorescent micrographs of the osteoblasts cultured on the scaffolds after day 1, day 3 and day 6 are shown in figures $2-4$, respectively. It can be seen that the osteoblasts are all well attached to the pore surface of all the scaffolds and proliferate along the pore walls. After 6 days, the fluorescent micrographs of the osteoblasts were not clear because the cells attached on the scaffold became to form a layer on the scaffold surface. Figures 5-7 show the SEM morphologies of the cell layers on the scaffold at day 6 (figure 5), day 12 (figure 6) and day 21 (figure 7). It could be seen that the outer surface and inner surface of the pores were all covered by the cell layers and the layer became more continuous and thicker with time.
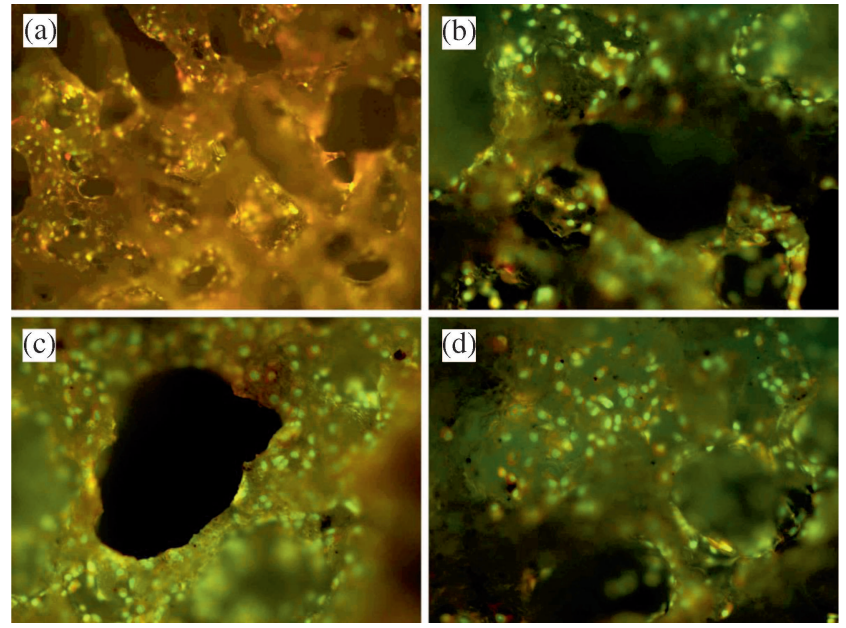

Figure 3. Fluorescent micrographs of the osteoblasts cultured on PDLLA scaffold (a) and PDLLA/pyrite scaffolds (b: PP5; c: PP10; d: PP20) after 3 days.
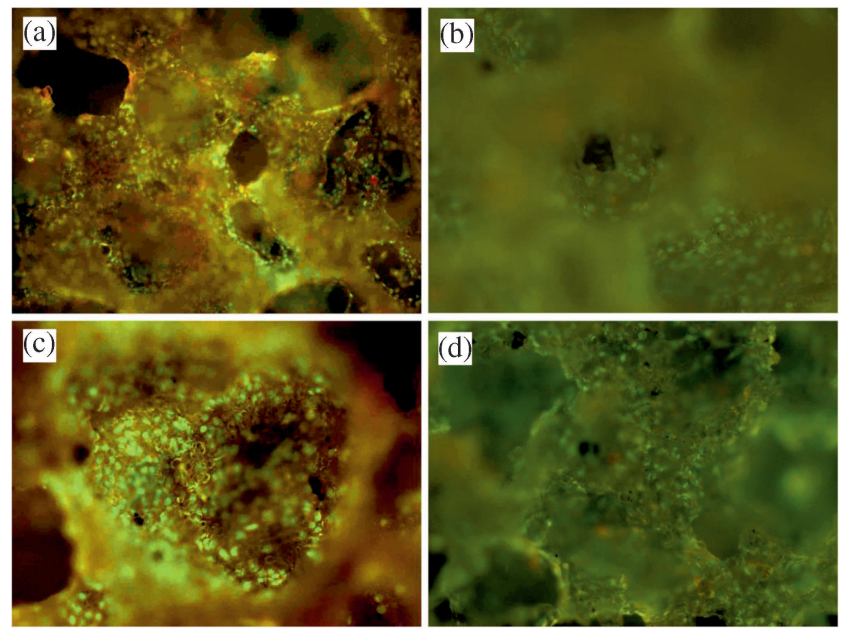

Figure 4. Fluorescent micrographs of the osteoblasts cultured on PDLLA scaffold (a) and PDLLA/pyrite scaffolds (b: PP5; c: PP10; d: PP20) after 6 days.

A MTT assay was also performed after days 1, 3, 6, 12 and 21 to determine cell proliferation on the scaffold. MTT is a pale yellow substrate that produces a dark blue formazan product when incubated with living cells. MTT ring is cleaved in active mitochondria, and the reaction occurs only in living cells. Figure 8 shows the results of the viability of osteoblasts cultured on the porous scaffolds measured by the MTT assay. It could be seen that the MTT absorption of all the samples increased over time thereby indicating cell proliferation on the scaffold until 12 days. After 12 days, the cells attached on the scaffold and the cells of the negative control group became to form a layer, and the cell proliferation of these cell layers could not be tested by the MTT method correctly and properly. The optical density (OD) values of the scaffold PP5 were statistically significant higher $(p<0.05)$ than the pure PDLLA scaffold at 

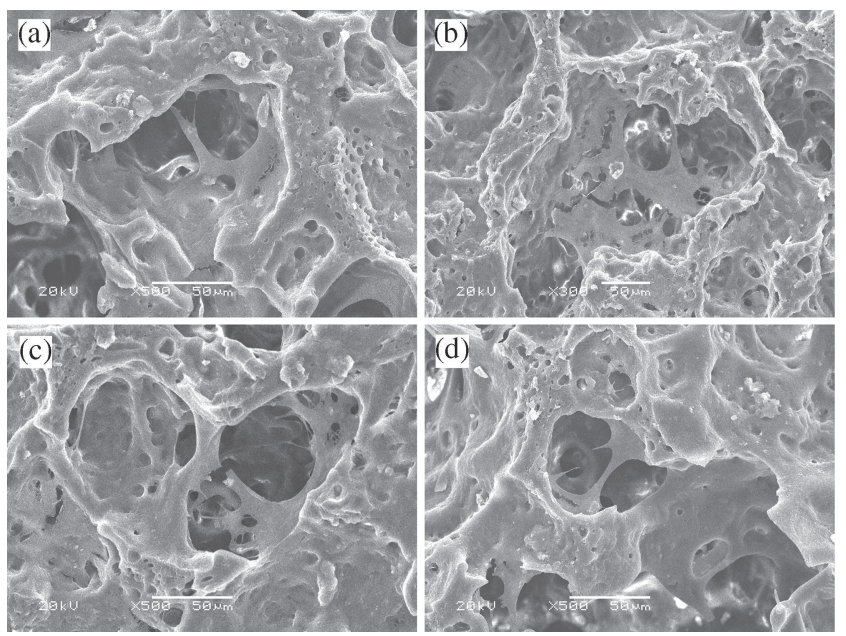

Figure 5. SEM photographs of the osteoblasts cultured on PDLLA scaffold (a) and PDLLA/pyrite scaffolds (b: PP5; c: PP10; d: PP20) after 6 days.
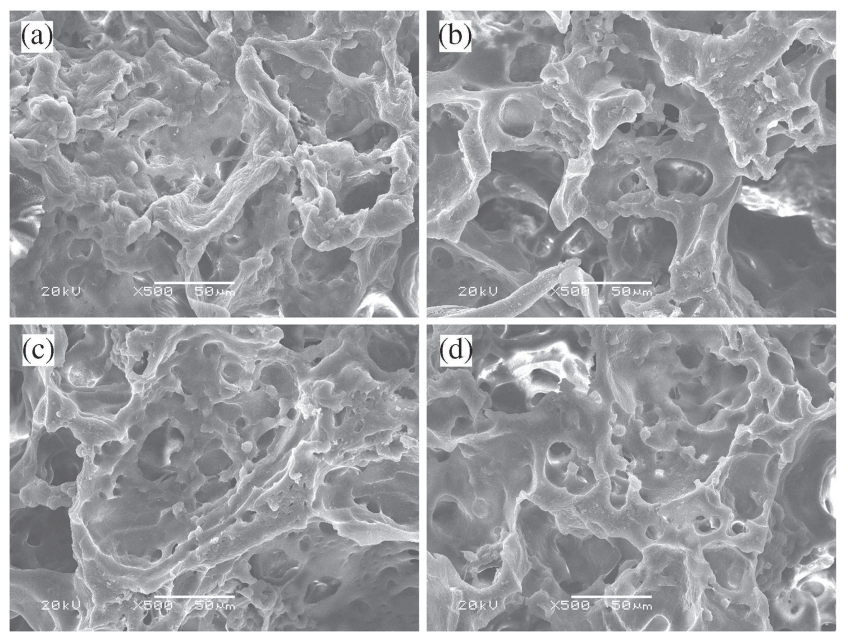

Figure 6. SEM photographs of the osteoblasts cultured on PDLLA scaffold (a) and PDLLA/pyrite scaffolds (b: PP5; c: PP10; d: PP20) after 12 days.

1, 3, 6 and 12 days. The scaffold PP10 and PP20 attained a significant high level at 21 days but they did not show a significantly high level before 12 days. From the MTT assay, the ROS17/2.8 cells cultured on PDLLA/pyrite scaffolds did not exert cytotoxic responses, providing an indication of good biocompatibility of PDLLA/pyrite scaffold. Noticeably, the growth of cells on PDLLA/pyrite scaffold containing 5\% pyrite was prior to cells cultured with PDLLA scaffold or without materials.

\subsection{ALP activity}

ROS17/2.8 cells on porous scaffold were assayed for retention of their osteoblast-like phenotype by ALP activity assay.
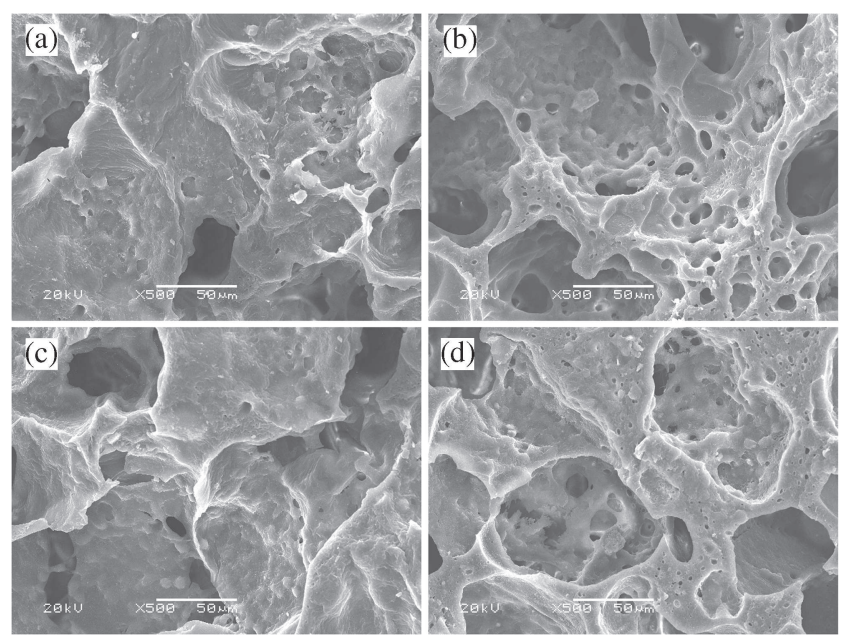

Figure 7. SEM photographs of the osteoblasts cultured on PDLLA scaffold (a) and PDLLA/pyrite scaffolds (b: PP5; c: PP10; d: PP20) after 21 days.

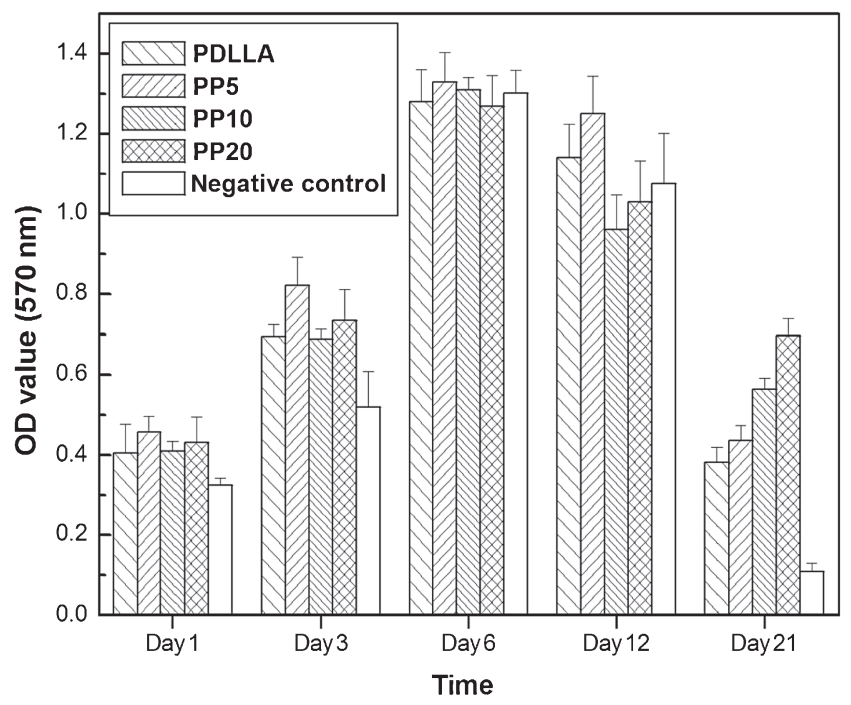

Figure 8. MTT absorbance of the ROS17/2.8 cultured on PDLLA scaffold and PDLLA/pyrite scaffolds PP5, PP10 and PP20.

When osteoblasts were cultured with scaffold for 1 day, there were no statistically significant differences between the PDLLA/pyrite scaffold and the pure PDLLA scaffold. At 3, 6 and 12 days, the growth of cells on the scaffold PP5 showed statistically significant high level $(p<0.05)$ in ALP activity as compared to the PDLLA scaffold (figure 9). And the growth of cells on the scaffold PP10 and PP20 all showed statistically significant low level $(p<0.05)$ in ALP activity as compared to the PDLLA scaffold. Associated with the results of ALP activity, only the scaffold PP5 containing $5 \%$ pyrite notably stimulated the expression of ALP. 


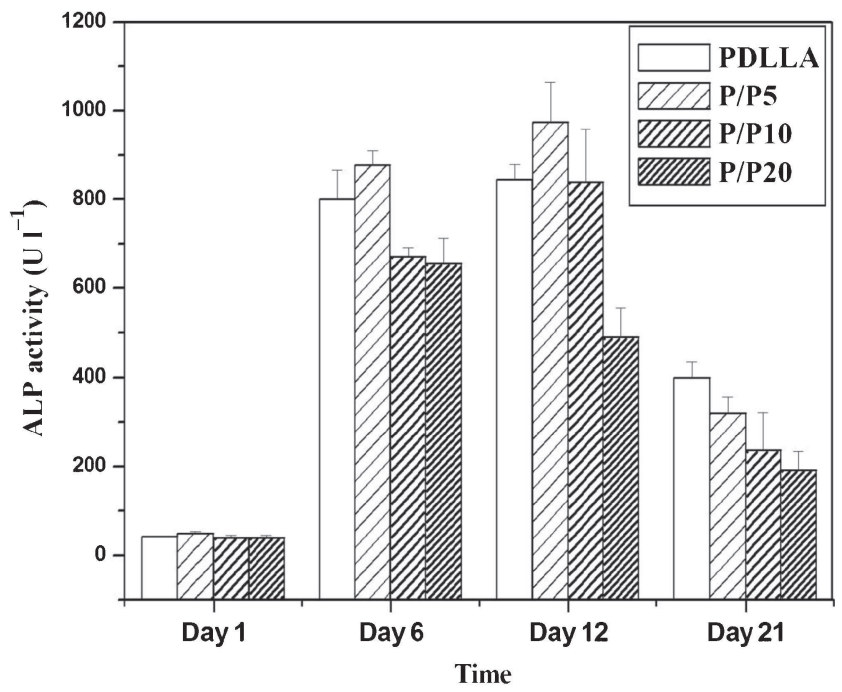

Figure 9. ALP activity of the ROS17/2.8 cultured on PDLLA scaffold and PDLLA/pyrite scaffolds PP5, PP10 and PP20.

\section{Conclusions}

A series of well-developed porous PDLLA/pyrite scaffolds were fabricated by particle leaching combined with the TIPS method. The mechanical properties of the scaffold were significantly enhanced by the pyrite particles in this study. Our findings demonstrated that PDLLA/pyrite was biocompatible with ROS17/2.8 cells in vitro as evaluated by cytotoxicity, proliferation, differentiation and morphological analyses. The scaffold PP5 containing 5\% pyrite was the optimal scaffold from the results of this paper. Although the mechanism why pyrite stimulated the growth of osteoblasts remained to be determined, these findings strongly suggested that by adding proper dose of pyrite into biodegradable materials, it was beneficial to the growth of cells and bone repair, so PDLLA/pyrite scaffold could be potentially used as a scaffold for bone tissue engineering.

\section{Acknowledgements}

This work was funded by Chengdu Institute of Organic Chemistry, Chinese Academy of Sciences. We thank Tanyan Fei for his help in cell culture experiments.

\section{References}

1. Tabata Y 2000 Pharm. Sci. Technol Today 380

2. Malafaya P B, Silva G A, Barana E T and Reis R L 2002 Curr. Opin. Solid State Mater. Sci. 6283

3. Sun R, Zhang L F, Du J and Xiong C D 2004 Chin. J. Synth. Chem. 6536

4. Ignjatovic N, Tomic S, Dakic M, Miljkovic M and Uskokovic D 1999 Biomaterials 20809

5. Shikinami Y and Okuna M 1999 Biomaterials 20809

6. Zhang Z J, Cai B C, Li W D and Zhang W L 2005 Chin. Tradit. Herbal Drugs 3634

7. Zhang Z J and Cai B C 2005 J. Nanjing TCM Univ. 2166

8. Zhang H F 1996 J. Nanjing TCM Univ. 1259

9. Huang H F and You J S 1997 Am. J. Chin. Med. 25351

10. Feng W and Fu W Y 2004 J. ZheJiang Coll. Tradit. Chin. Med. 2865

11. David K and Vassilis K 2005 Biomaterials 265474

12. Molly M S, Hala F Q, Robert L and Prasad S V 2004 Biomaterials 25887 